\title{
Do we really know what we are building? Raising awareness of potential Sustainability Effects of Software Systems in Requirements Engineering
}

\author{
Leticia Duboc \\ La Salle \\ University Ramon Llull \\ Barcelona, Spain \\ l.duboc@salle.url.edu \\ Sedef Akinli Kocak \\ Vector Institute for Artificial Intelligence \\ Toronto, Canada \\ sedef.kocak@vectorinstitute.ai \\ Jari Porras \\ Lappeenranta University of Technology \\ Lappeenranta, Finland \\ jari.porras@lut.fi
}

\author{
Stefanie Betz \\ Hochschule Furtwangen University \\ Furtwangen, Germany \\ besi@hs-furtwangen.de
}

Ruzanna Chitchyan

University of Bristol

Bristol, UK

r.chitchyan@bristol.ac.uk

\author{
Norbert Seyff \\ FHNW \\ Switzerland \\ norbert.seyff@fhnw.ch
}

\author{
Birgit Penzenstadler \\ Chalmers University of Technology \\ Gothenburg, Sweden \\ birgitp@chalmers.se
}

\author{
Ola Leifler \\ Linköpings Universitet \\ Linköping, Sweden \\ ola.leifler@liu.se
}

Colin C. Venters

University of Huddersfield

Huddersfield, UK

c.venters@hud.ac.uk

\begin{abstract}
Integrating novel software systems in our society, economy, and environment can have far-reaching effects. As a result, software systems should be designed in such a way as to maintain or improve the sustainability of the sociotechnical system of their destination. However, a paradigm shift is required to raise awareness of software professionals on the potential sustainability effects of software systems. While Requirements Engineering is considered the key to driving this change, requirements engineers lack the knowledge, experience and methodological support for doing so. This paper presents a question-based framework for raising awareness of the potential effects of software systems on sustainability, as the first step towards enabling the required paradigm shift. A feasibility study of the framework was carried out with two groups of computer science students. The results of the study indicate that the framework helps enable discussions about potential effects that software systems could have on sustainability.

Keywords: sustainability, software, socio-technical systems, requirements engineering
\end{abstract}

\section{Introduction}

Software underpins all aspects of societal life from commerce, communication, education, to energy, entertainment, finance, governance and defence etc. As a cornerstone of various socio-technical systems, the software is also a key driver in their sustainability: their capacity to endure within the current economic, environmental, social, technical, and individual settings. These are commonly referred to as the five dimensions of sustainability [24]. As a result, the sustainability of a socio-technical system should become a prime concern for the Software Engineering discipline. To demonstrate how software can affect the sustainability of a social system within which it is placed, let us look at the example of the Airbnb platform in New York.

Motivating Example: Airbnb offers a peer-to-peer short-term accommodation booking platform [1]. It allows property owners to rent out homes or rooms to visitors. Recent research [32] shows that in New York, homeowners who rent their house frequently can earn $55 \%$ more than the median long-term rental in the same neighbourhood (affecting the individuals and the economy). As a consequence, it is estimated that Airbnb has removed between 7,000 and 13,000 units of housing in New York from the long-term rental market, leading to an increase of $1.4 \%$ in the median long-term rent (affecting the society and the economy). Research has also shown that in New York, 72\% of the population in the neighbourhoods at the highest risk of Airbnb-induced gentrification are non-white, increasing the race separations across the city (affecting the society). The main reason for developing the Airbnb platform was to provide an immediate benefit to travellers and property owners through a direct software function. Over time, the system offers additional benefits to owners (more earnings) and travellers (cheaper accommodation, authentic local experience). It has also led to economic and social impacts which were not considered at the time of its deployment. Usually, these types of effects are only noticed in hindsight and considering such possibilities ahead of software deployment is considered to be an expensive undertaking.

This paper advocates that as major drivers of change 
within society, software systems must be designed to maintain the sustainability [3] of the wider socio-technical system in which they are integrated. As such, it is the responsibility of requirements engineers to analyse the sustainability impacts of the software across all dimensions and inform the software design process of the potential (un-)desired consequences. This requires a paradigm shift in requirements engineering practice, in which software and requirements engineers take explicit responsibility for the technological solutions that they introduce into society. For that, they can draw upon the lessons of tackling wicked problems from a holistic perspective of systems thinking [9] instead of insisting on the narrow computational thinking mindset of "solving a problem for a customer" [14].

Systems Requirements Engineering (RE) is the key to this change of paradigm [3] and must start by raising awareness of the relationships between a software system and sustainability. As such, our key contributions are:

1) A question-based "Sustainability Awareness Framework" for raising awareness of the impacts that a software system could have upon sustainability.

2) An evaluation of the proposed question-based framework based on two instances of its application as part of a teaching curriculum.

The paper is organised as follows: Section 2 explains sustainability-related concepts; Section 3 describes our framework; Section 4 outlines the study design; Section 5 presents its results; Section 6 summarises the related work; finally Section 7 examines of the study.

\section{Sustainability and Related Concepts}

Modern society's reliance on software systems has resulted in the emergence of sustainability as a growing area of interest in the field of software and requirements engineering [31]. In the context of this paper, sustainability is defined as the capacity of a socio-technical system to endure [3].

Two closely related concepts are sustainable use and sustainable development. Hilty and Aebischer [16] define sustainable use of a system $\mathbf{S}$ with regard to a function $\mathbf{F}$ and a time horizon $\mathbf{T}$, which in essence means to "use $\mathbf{S}$ in a way that does not compromise its ability to fulfil $\mathbf{F}$ for a period of T". As a result, the concept of sustainable use is relative as it is dependent on how $\mathbf{S}, \mathbf{F}$ and $\mathbf{T}$ are defined in context. The Brundtland Commission defined sustainable development [7] as "meeting the needs of the present without compromising the ability of future generations to meet their own needs". The word 'need' is central to this definition and includes a dimension of time: present and future, as well as acknowledging the concept of changing stakeholder requirements. While it may appear that sustainable development is a special case of sustainable use, it has an element of distributive justice where "the essential needs of the world's poor are given overriding priority.

It is argued that the controversy around how sustainability is defined [30] is the result of how people think about the different perspectives of systems $\mathbf{S}$ and functions
$\mathbf{F}$ to be sustained over different time horizons $\mathbf{T}$ by not explicitly declaring them in the discourse of designing a technological artifact [16]. To address this, it is suggested that any actions referring to sustainability should answer the following questions: What is to be sustained? For whom? For how long? And at what cost?

The Karlskrona Manifesto [5] provides a focal point for establishing a common ground for the requirements engineering community to engage with sustainability by advocating a set of fundamental principles and commitments that underpin sustainability design. It includes the importance of recognising that sustainability is an explicit consideration, even if the primary focus of the system under design is not sustainability. It also advocates that sustainability must be viewed as a construct across five dimensions environmental, economic, individual, social and technical and consider the potential long term effects of systems.

\section{Sustainability Awareness Framework}

The sustainability awareness framework is composed of a diagram and five-question sets for guiding semi-structured interviews, as discussed below.

\subsection{Sustainability Awareness Diagram}

To visualise the effects that a software system could have on the sustainability of its socio-technical environment, we use an adapted radar chart (in line with [3]), which we refer to as the Sustainability Awareness Diagram (SusAD). The diagram is a visualisation tool which breaks down the radar chart graph into the five interrelated dimensions of sustainability. Each dimension is further divided into three order of effects, denoting the effect that a software system can cause across time; These are: immediate (i.e., caused by the direct function of the system or its development), enabling (i.e., arising from the application of a system over time), or structural (i.e., referring to persistent changes that can be observed at the macro level) [16]. These are illustrated starting with the immediate effect in the centre, the enabling in the middle, and the structural at the external layer of the diagram (see Figure 1).

Let us exemplify the use of the diagram through the Airbnb example presented in Section 1, and now illustrated in Figure 1. As its immediate technical use effect, Airbnb allows property owners to rent out their homes or rooms. As a result of persistent rental via Airbnb, homeowners earn $55 \%$ more than the median long-term renting, which is an enabling effect upon individuals. Increased median longterm rent due to reduced long-term rental accommodation stock is a structural economic effect of this platform. Finally, the gentrification of primarily non-white localities and increased race separation is its' structural social effect.

A SusAD diagram would normally have several chainof-effects, showing how one aspect of the software system use (e.g., renting rooms out) causes other consequences (e.g., removal of non-white communities and deepened social segregation). Filling the diagram out without any 


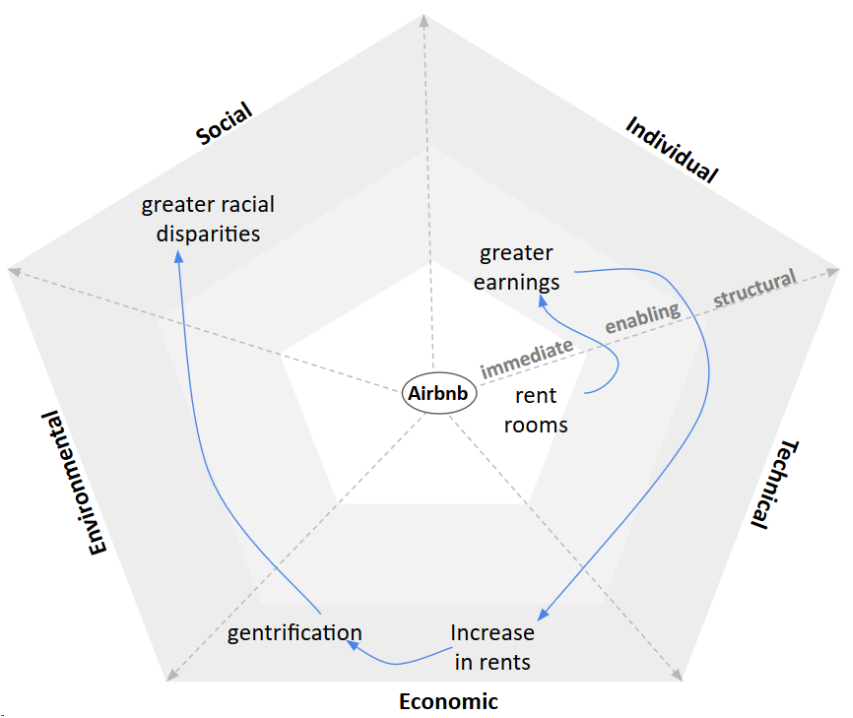

Figure 1. Simplified SusAD diagram for AirBnB system

guidance, however, can be a daunting task, as it is not easy to elicit the required information. This is especially the case as the requirements engineers are not trained to consider sustainability issues [11]. The question-based framework proposed below aims to facilitate SuSAD diagram construction and use to further discussions of sustainability-related impacts between socio-technical system stakeholders.

\subsection{Questions Framework}

1) Instructions for the interviewer detailing the interview process, e.g., consent to record and collect data, need to consider chains-of-effects, etc.

2) Questions sheets for each sustainability dimension, containing questions in plain text, examples, reminders and checkboxes. The sheet also suggests prompts to encourage the interviewee to think further, and examples to clarify some of the questions. E.g. prompt is: "You mention how the system gives the same treatment to people, what about taking actions to ensure the outcome for each person is comparable?". A clarifying example would be: "Systems sometimes enable the co-creation or codestruction of value when a customer interacts with the business. For example, [...] when a customer cannot self-serve as expected, her experience is affected [...]. Does the system enables this kind of co-creation or co-destruction of value?"

3) One note-taking form per dimension for the interviewer to capture and record key effects and dependencies throughout the conversation.

4) Questions for the interviewee, to help respondents to follow the interview process (same as asked by the interviewer, but without prompts).

When creating the questions sheets, we did not aim to have an exhaustive list of topics or questions to address every aspect of sustainability (which is quite impossible). Instead, we aimed to give requirements engineers a starting point for discussing possible sustainability effects. Thus, we chose to cover only five topics for each dimension, although additional (system and domain-specific) topics could well arise for each dimension as the interview progresses. Our starting sample of topics is listed in the Table 1.

\begin{tabular}{l|l} 
Social & $\begin{array}{l}\text { (1) Sense of Community; (2) Trust; (3) Inclusiveness and } \\
\text { Diversity; (4) Equality; (5) Participation and Communica- } \\
\text { tion; }\end{array}$ \\
\hline Individual & $\begin{array}{l}\text { (1) Health; (2) Lifelong learning; (3) Privacy; (4) Safety; } \\
\text { (5) Agency; }\end{array}$ \\
\hline Environmental & $\begin{array}{l}\text { (1) Material and Resources; (2) Soil, Atmospheric and Water } \\
\text { Pollution; (3) Energy; (4) Biodiversity and Land Use; (5) } \\
\text { Logistics and Transportation; }\end{array}$ \\
\hline Economic & $\begin{array}{l}\text { (1) Value; (2) Customer Relationship Management (CRM); } \\
\text { (3) Supply chain; (4) Governance and Processes; (5) Inno- } \\
\text { vation and R\&D; }\end{array}$ \\
\hline Technical & $\begin{array}{l}\text { (1) Maintainability; (2) Usability; (3) Extensibility and } \\
\text { Adaptability; (4) Security; (5) Scalability; }\end{array}$ \\
TABLE 1. TOPICS COVERED BY QUESTIONS IN EACH DIMENSION
\end{tabular}

Figure 2 exemplifies the questions for social dimension. The forms can be found in [13].

\subsection{Extreme Scenarios and Chains of Effects}

The questions (exemplified in Figure 2) are intended to help uncover possible immediate and longer-term effects. In order to encourage identification of such impacts, the framework complements questions with a simple note-taking form (shown in Figure 3) which explicitly draws the attention of the interviewer to noting down the chains-of-effects.

Yet, interviewees might not consider long-term, compounded impacts. To foster this, the framework suggests posing an imaginary "extreme" scenario, where the intended software system is accepted and used by millions of people worldwide for a long period of time. The interviewee is then invited to reflect on the impact that such a widespread, long-term use of the system may have. For example, "Imagine that many people worldwide are using this system for decades. Think about how one thing may lead to another. We call this a chain of effects. If people feel closer to their neighbours, they may choose to buy from local shops or choose proximity products, which can then foment local businesses, and finally better distribute wealth."

\section{Research Methodology}

This section describes how we have designed the Sustainability Awareness Framework and evaluated the feasibility of its use. The emphasis is on the clarity and utility of the question sets for eliciting potential effects of software systems on sustainability. For this, the following research questions were addressed:

RQ1: Does the framework encourage insightful discussions about the potential effects of software systems on sustainability? 
SOCIAL DIMENSION (Interviewer copy. Tick questions as you advance in the interview.)

\begin{tabular}{|c|c|}
\hline Specific Questions & Remind participants to consider... \\
\hline $\begin{array}{l}\text { SENSE OF COMMUNITY } \\
\text { [ ] Normally people belong to an organization, to an area or to a group of } \\
\text { like-minded people. Can the system affect a person's sense of belonging to } \\
\text { these groups? }\end{array}$ & $\begin{array}{l}\text { [ ] the user community and the local community. } \\
\text { Say, for example: you mentioned an effect on the sense of community of the user. } \\
\text { What about the people in the local community? }\end{array}$ \\
\hline $\begin{array}{l}\text { TRUST } \\
\text { [ ] Can the system change the trust between the users and the business that } \\
\text { owns the system? } \\
\text { [ ] What about the trust between the users themselves? }\end{array}$ & $\begin{array}{l}\text { [ ] user groups and other groups in the society. } \\
\text { Say, for example: you mentioned an effect on how people trust the business. What } \\
\text { about how other groups in the society that don't interact with the system trust each/ } \\
\text { other? }\end{array}$ \\
\hline $\begin{array}{l}\text { INCLUSIVENESS AND DIVERSITY } \\
\text { [ ] Can the system impact on how people perceive others? } \\
\text { [ ] Does the system include uses with different backgrounds, age groups, } \\
\text { education levels, or other differences? } \\
\text { [ ] Does the system caters for these differences? How? }\end{array}$ & $\begin{array}{l}\text { [ ] user groups and other groups in the society. } \\
\text { Say, for example: you mentioned an effect on the perception of the user. What about } \\
\text { other groups on the society? }\end{array}$ \\
\hline $\begin{array}{l}\text { EQUALITY } \\
\text { [ ] Can the system make people to be treated differently from each other? For } \\
\text { example, because the system carries out data analytics or influences } \\
\text { human decisions. }\end{array}$ & $\begin{array}{l}\text { [ ] equality of opportunity }{ }^{1} \text { and of outcome }{ }^{2} \text {. } \\
\text { Say, for example: you mention how the system gives the same treatment to people }{ }^{1} \text {, } \\
\text { what about taking actions to ensure the outcome for each person can be the same }{ }^{2} \text { ? } \\
\text { For example, putting in place support, communicating in different ways, giving access } \\
\text { to resources, respecting decisions, recognizing, valuing and respecting differences. } \\
\text { [ ] user groups or other groups in the society. } \\
\text { Say, for example: you mentioned how users are treated by the system. Does the } \\
\text { system makes other groups in the society to be treated differently or equally? }\end{array}$ \\
\hline $\begin{array}{l}\text { PARTICIPATION AND COMMUNICATION } \\
\text { [ ] Can the system change the way people participate in an organization or } \\
\text { other social groups? } \\
\text { [ ] Does it affect the way people communicate verbally and non-verbally? } \\
\text { [ ] Does it affect the way people create networks? } \\
\text { [ ] Does it affect the way people form bounds? } \\
\text { [ ] Does it affect the effort people put in a group work }{ }^{1} \text { ? } \\
\text { [ ] Does it affect the actions people take to achieve the goals, projects and } \\
\text { tasks of a group? } \\
\text { [ ] Does it affect the way people engage with others? } \\
\text { [ ] Does it affect the way people support, consider, critique or argue with } \\
\text { others? } \\
{ }^{1} \text { social loafing }\end{array}$ & $\begin{array}{l}\text { [ ] the users, the beneficiaries and other people affected by the system. } \\
\text { Say, for example: you mentioned how users change their way to participate or } \\
\text { communicate in groups. }\end{array}$ \\
\hline
\end{tabular}

Figure 2. Front page of the question sheet for the social dimension

\begin{tabular}{|c|c|}
\hline Topic & Key Points - Social Dimension \\
\hline \multirow{6}{*}{ 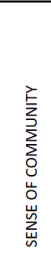 } & $\begin{array}{l}\text { rent rooms } \rightarrow \text { personal contact } \rightarrow \text { start friendship } \rightarrow \text { better } \\
\text { sense of community }\end{array}$ \\
\hline & rating system $\rightarrow$ welcome and helpful \\
\hline & high use $\rightarrow$ change house dynamics $\rightarrow$ children affected \\
\hline & high use $\rightarrow$ door codes $\rightarrow$ less personal contact \\
\hline & structural changes to properties \\
\hline & high use $\rightarrow$ long-term renters forced out \\
\hline
\end{tabular}

Figure 3. Extract of the notes taking form

RQ2: Does the framework help to identify the potential chains-of-effects of software systems on sustainability?

RQ3: How practical is the proposed approach?

\subsection{Design of Question Sets}

To elicit the question sets, we used an adaptation of the Delphi method [17], [22]. Here, the members of the Karlskrona Alliance on Sustainability Design [4] acted as the panel of experts, as they have worked on topics of sustainability for over six years, focusing on various domains, ranging from social sustainability to energy, and impacts of technology transfer.

The facilitator (first author of this paper) set out an online document and invited panel members to contribute views on factors that affect the five dimensions of sustainability, and questions that a requirements engineer should consider regarding these factors. Two example software systems - Airbnb and a procurement system - were used to ground the discussions. Airbnb was chosen as it is a generally well known and commonly used system, whereas the procurement system was studied by the panel of experts in a previously reported work [3]. The panel then worked through three rounds of activities to converge on the final question sets: The first (contribution) round started with the panel members providing their views by directly editing a document and populating questions. In this round of question elicitation, the panel members were asked to write down their own contributions, without any other concern. The facilitator closed this round when all the contributors felt they had listed the most important issues. She then reviewed all the questions, removed repetitions and rephrased the questions for better readability. She also consulted selected literature (previously suggested by the panel) to refine the questions. These materials then constituted the result of the 
first round.

At the second (review) round, the panel was requested to review and comment on all of the results of the first round. Two weeks were allocated for this round, enabling panel members to contribute their views asynchronously. This resulted in a number of issues raised with regards to previously expressed views/proposed questions (e.g., noting unclear statements, pointing out further implications of the noted event/question, restating leading questions, disagreements with the questions, etc.). The facilitator closed this round when all panel members stated that they had completed their reviews.

The third (consensus) round in the question elicitation process started by the panellists reflecting on the feedback given by others, and reviewing their views in this light. The process continued with the clarifications and resolution of the issues raised. This round was carried out through online small group meetings, where two to four panellists met to discuss the raised concerns. The round terminated when all raised issues were resolved, and all panel members were satisfied with the derived questions set.

\subsection{Research Design for Question Evaluation}

The feasibility study consisted of using the Sustainability Awareness Framework with two groups of students from different universities and countries in the spring of 2019. At both universities, the students were provided with the same sets of instructions, question sheets, and surveys.

Set Task: Students were instructed to carry out at least one interview per sustainability dimension, for a software system of their choice (i.e., whichever system they may wish to select from their own environment). They were to follow the process and use the material described in Section 3.2 and also to fill out a SusAD diagram with the most interesting (in their view) chain-of-effects. We note that (i) since there are five sustainability dimensions, at least five interviews are to be carried out by each student group; (ii) we generally expect that each dimension would be represented by a different (at least one) stakeholder. Upon interview completion, the feedback was collected from each interviewee, as well as from the interviewer about the question-set for that specific dimension.

At the California State University, Long Beach (CSULB), thirty-one students worked in nine groups, in a writing-intensive third-year course on ICT for Sustainability. Of these, thirty students were studying computer science and one environmental management and engineering. The assignment was introduced in class and explained with a number of example diagrams as well as a mock interview with a research assistant.

At Lappeenranta University of Technology (LUT), sixteen students worked in nine 1-2 person teams. The task was carried out as part of an MSc level course on Sustainability and IT. Here all students had an IT background. The task was introduced in class and explained with several examples on the topic.
In both settings, the students had two weeks to carry out the interviews, create a summary SusAD diagram and to write a report, aggregating the information from their interviews and discussing their reflections. This work was carried out by the students independently, and they could approach the researchers in case of questions.

4.2.1. Data Collection. We collected data from the feasibility study by means of two surveys. The first one was answered after each interview and contained the feedback of the interviewer and the interviewee about the questions. To collect the impression of the interviewee, students were instructed to ask two additional questions at the end of the interview and to summarise their answers in the online survey. Since the student groups had to carry out at least one interview per dimension, we received 57 responses: 23 from CSULB and 34 from LUT.

The second survey was answered after the group filled out the SusAD diagram; it was meant to gather the collective feedback of the group regarding the SusAD framework. It was expected that each group would submit a single response, but some students preferred to submit individual responses. In total, 26 responses were received: 18 from CSULB and 8 from LUT.

The students were also required to deliver a SusAD for what they considered to be the most interesting chains-ofeffects and a textual list of the remaining ones.

All surveys were collected via Google forms. The diagrams and reports were collected via Dropbox at CSULB and Moodle (a learning management system) at LUT. The survey data was anonymous but reported on the system that the group had been working on. Since the groups were working on a different system, we were able to relate the survey responses to the group work submission.

4.2.2. Data Analysis. We start with an explanation of (a) how survey questions are mapped to Research Questions, then we describe (b) how the quantitative values have been calculated, followed by an explanation of (c) how the qualitative data was used in the analysis.

Mapping survey questions to RQ: The two surveys [13] contained 35 questions in total. After most questions, students were asked to provide free text explanations of their choices. We grouped the survey questions in two categories: the first one is composed of questions that directly contribute to answering the RQs. These are shown in Table 2 and mapped to the RQs in Table 3. The second group contained qualifying questions that helped us to interpret the answers to the first category. Due to space constraints, these are not listed but are discussed in Section 5. For clearer traceability, each survey question was mapped only to the RQs that it most contributed to.

Note that the questions come from two surveys: (i) conducted after the interview and (ii) conducted after depicting the SuSAD. This allows us to have three data points for drawing conclusions on some of the questions: the feedback of interviewees, interviewers and the group as a whole. 


\begin{tabular}{|c|c|c|c|c|c|}
\hline \multicolumn{2}{|c|}{ (a) After each interview } & Type & \multicolumn{2}{|c|}{ (b) After the SusAD } & Type \\
\hline \multicolumn{3}{|c|}{ Interviewer } & \multicolumn{3}{|c|}{ Group } \\
\hline a.1 & Have you understood the questions? & Likert & b.1 & $\begin{array}{l}\text { Did you get access to the right stakeholders? [ } \\
\text { per dimension] }\end{array}$ & $\mathrm{y} / \mathrm{n} / \mathrm{p}$ \\
\hline a.2 & $\begin{array}{l}\text { Has the interviewee had difficulties in answering } \\
\text { the questions? }\end{array}$ & (Likert) & b. 2 & $\begin{array}{l}\text { Have the questions helped to identify possible } \\
\text { effects? }\end{array}$ & $\mathrm{y} / \mathrm{n}$ \\
\hline a.3 & $\begin{array}{l}\text { Did the questions enable discussions with the in- } \\
\text { terviewees? }\end{array}$ & Likert & b. 3 & $\begin{array}{l}\text { How did you like the process of asking the ques- } \\
\text { tions, noting down the key points and sowing them } \\
\text { back to the interviewee? }\end{array}$ & Likert \\
\hline a.4 & $\begin{array}{l}\text { Did you get insightful answers using the questions } \\
\text { in this particular domain? }\end{array}$ & Likert & b. 4 & Did the questions help to fill out the SusAD? & Likert \\
\hline a.5 & $\begin{array}{l}\text { Have the interviewees been able to think of chains } \\
\text { of effects for the extreme scenario? }\end{array}$ & Likert & b.5 & Was the resulting SusAD readable? & Likert \\
\hline \multicolumn{6}{|c|}{ (a) Interviewee } \\
\hline a.6 & \multicolumn{4}{|c|}{ Were the questions easy to understand? } & text \\
\hline a.7 & \multicolumn{4}{|c|}{ Have the questions been useful for triggering relevant discussions on the possible effects of software systems? Why? } & text \\
\hline
\end{tabular}

TABLE 2. SURVEY QUESTIONS THAT DIRECTLY CONTRIBUTED TO RQS

\begin{tabular}{|c|c|}
\hline Research question & $\begin{array}{l}\text { Survey ques- } \\
\text { tions }\end{array}$ \\
\hline $\begin{array}{l}\text { RQ1: Does the framework encourage insightful discussions about } \\
\text { the potential effects of software systems on sustainability? } \\
\text { Aim: see if questions help to uncover new, previously unconsid- } \\
\text { ered info. }\end{array}$ & a. 3, a. 4, a. 7 \\
\hline $\begin{array}{l}\text { RQ2: Does the framework help to identify potential chain of } \\
\text { effects of software systems on sustainability? } \\
\text { Aim: see if questions provide sufficient informaiton for chains of } \\
\text { effects and SuSAD diagram. }\end{array}$ & b. 2, a. 5 \\
\hline $\begin{array}{l}\text { RQ3: How practical is the proposed approach? } \\
\text { Aim: look into the phrasing, access to expertise, the structure, } \\
\text { and the process of the proposed approach }\end{array}$ & 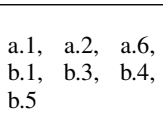 \\
\hline
\end{tabular}

TABLE 3. MAPPING BETWEEN RQS AND SURVEY QUESTIONS

Calculating quantitative results: We used three types of closed-questions in the surveys: binary (yes/no), tertiary (yes/no/partially) and a 5-points Likert scale. In order to analyse them and define their contribution to the RQs, we mapped responses to numerical values, calculating the averaged and normalising on a scale from 1 to 5 as follows:

- Binary responses $(\mathrm{y} / \mathrm{n})$ were re-scaled as averages over a 5-point scale: yes mapped to 5, no mapped to 1 .

- Tertiary responses $(\mathrm{y} / \mathrm{n} / \mathrm{p})$ were normalised to 3 point range in the range $1-5$, where No maps to 1 , Partially maps to 3, and Yes maps to 5.

- The 5-points Likert scale questions had two cases: some were asked with a "positive phrasing" (e.g. "Have you understood the questions?"), meaning that a higher value would support RQ. These were simply mapped from 1 to 5 . Others were asked with a "negative phrasing" (e.g. "Has the interviewee had difficulties in answering the questions?"), meaning that a higher value would oppose the RQ. To calculated the contribution of a negative question, we have used the six-complement (i.e. a "2" would become a "4"). In order to differentiate them, "negativelyphrased", the type of this questions are marked with brackets; for example "(Likert)".

For answering the research questions, we mapped average values from survey questions to a scale of support to the Research Questions (RQs). There are five points in the scale to which the values are mapped (using equal

\begin{tabular}{l|l} 
Scale & Value range \\
\hline Strongly oppose (SO) & $1-1.7$ \\
Oppose (O) & $1.8-2.5$ \\
Inconclusive (I) & $2.6-3.3$ \\
Support (S) & $3.4-4.1$ \\
Strongly support (SS) & $4.2-5$ \\
4. MAPPING OF THE VALUES TO THE SCALE OF SUPP
\end{tabular}

TABLE 4. MAPPING OF THE VALUES TO THE SCALE OF SUPPORT

intervals): Strongly Oppose (SO), Oppose (O), Inconclusive (I), Support (S), and Strongly Support (SS) - see Table 4. Analysing qualitative results: Since nearly every survey question also asked to provide free text explanations for the choice of the scale value, a substantial amount of text was also collected for qualitative analysis. This text was coded using a set of codes defined for each survey question, following the qualitative content analysis approach [18].

Two researchers created the codebook, and collaboratively analysed the free-text responses from CSULB, after which the coding was validated by two additional researchers. The codebook was reused for analysis of survey data from LUT. Double-coding was used if a given free-text response related to several code categories. For example, the answer "I would need to interview more people with different expertise" would be coded as "more_interviews" and "different_expertise".

Table 5 shows an extract from the codebook, which contains the RQ it refers to, the survey question, whether the contribution of the code towards the question is "positive" or "negative", the code, and the number of occurrences for both universities. This qualitative data was used for interpreting the respondents' choices.

\begin{tabular}{|c|c|c|c|c|c|}
\hline \multirow[t]{2}{*}{ RQ } & \multirow{2}{*}{ SQ } & \multirow[t]{2}{*}{ cont. } & \multirow[t]{2}{*}{ codes } & \multicolumn{2}{|c|}{ occur. } \\
\hline & & & & $\mathbf{A}$ & B \\
\hline \multirow{9}{*}{ RQ1 } & \multirow{9}{*}{ a.7 } & pos. & useful_to_expand_on_topic & 10 & 12 \\
\hline & & neg. & useful_some_not_relevant_for_system & 2 & 3 \\
\hline & & pos. & useful_for_future & 2 & 5 \\
\hline & & pos. & useful_because_detailed & 2 & 2 \\
\hline & & neg. & useful_insufficient_expertise & 1 & 2 \\
\hline & & pos. & useful_because_vague & 1 & 1 \\
\hline & & pos. & useful_to_take_action & 0 & 1 \\
\hline & & pos. & useful & 0 & 4 \\
\hline & & pos. & useful_privacy & 1 & 0 \\
\hline
\end{tabular}




\subsection{Threats to validity}

Threats to validity hamper the ability to draw conclusions from the evidence [33]. For the Delphi study, the main risks come from the fact that the members of the panel were drawn from the same collaboration group. Thus, the breadth of the views to be represented in the question sets is biased towards the group's own view. Furthermore, the anonymity of the panel members was not preserved (as they know each other). This could cause a number of additional biases, where attitudes towards the individuals could have influenced the agreement or disagreement with their provided views. In the future, this might be mitigated by integrating input from experts from outside the group and validating the question set through wider participation. For the feasibility study, one of the main risks is the reactive bias, as the students might answer the questionnaire positively to meet the expectations of their teachers (i.e. halo effect). Additionally, there are several confounding factors which may affect the outcome that was not taken into account, such as differences in knowledge regarding sustainability issues of the students and the level of expertise of the interviewees. Since we worked with two different groups of students from two different universities, these factors cannot be ruled out completely. However, we endeavour to ensure a similar perspective on sustainability and knowledge of the questions and the SuSAD method by delivering the same introductory sessions and instructions to both groups. Another main risk is the possible bias caused by result interpretation. We applied researcher triangulation and mixed qualitative and quantitative methods to minimise this risk. Finally, we do not attempt to generalise the findings from these two application cases; we only demonstrate the feasibility of using the SuSAD for relating requirements engineering process to topics of sustainability.

\section{Results}

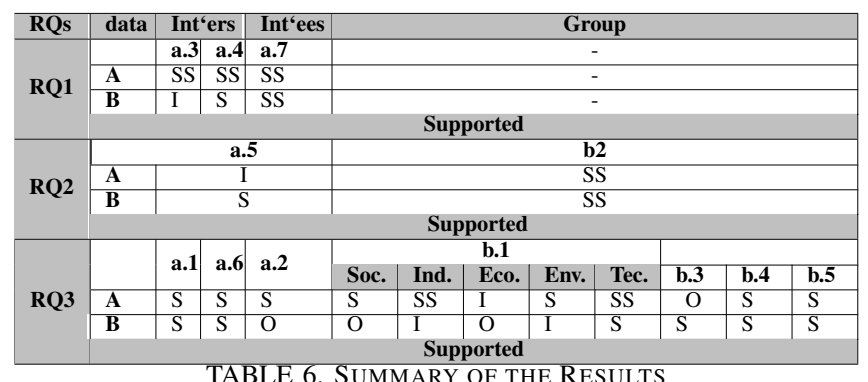

This section provides the results of our data analysis and how they answer the RQs. Table 6 summarises the extent to which the different surveys provided evidence for answering our RQs based on the quantitative data and based on the normalised answers to the survey questions. Next, we detail the answer to each research question. Average quantitative results that led us to the final conclusions about the support to a given concept are shown in brackets.
RQ1: Does the framework encourage insightful discussions about the potential effects of software systems on sustainability?

Three survey questions contributed to this RQ; the answers we received are summarised below. The first survey question asked whether the SusAD questions enabled discussions with the interviewee (a.3) and subjects supported (3.76) this notion, with strong support from CSULB and inconclusive support from LUT. Analysing the qualitative codes for that question (shown with occurrences in parenthesis), we observed that some students stated that the questions led to more questions (17\%, "lead_to_more_questions" $\mathrm{A}=7 \mathrm{~B}=3)$, and helped to elaborate the answers $(10 \%$, "elaboration" $A=2 B=4$ ), e.g. one respondent said: "They enabled, $[. .$.$] the interviewee could direct the direction of$ topic and voice his personal opinions without influence from $u s$ ". Furthermore, the questions were reported to be a good support (9\%, "good_support_from_questions" A=7 B=3), and to encourage an interviewee who is knowledgeable (12\% "knowledgeable_interviewee" $\mathrm{A}=2 \mathrm{~B}=3$ ) or passionate (5\% "enable_passionate_interviewee" $\mathrm{A}=2 \mathrm{~B}=1$ ) interviewee, e.g. "This topic is something the interviewee was very passionate about". We note a difference in the textual answers received from two universities, which could be due to the cultural difference in communication in California vs Finland: while in CSULB only one interviewee was described as terse, in the LUT, six interviewees and one interviewer received such description. This could also be observed in the difference in the number of codes generated for the data from these two universities. (Due to space constraints, we will no longer show the codes and occurrences related to qualitative findings, but all explanations to students' choices have been analysed in the same way as above.)

The second survey question asked whether insightful answers (a.4) had emerged using the questions in this particular domain. Again, the students supported (3.84) this notion, with strong support by CSULB and LUT. The most cited reason for getting good insights was the interviewee opening new perspectives about the domain (14\%), followed by having a lot to discuss (7\%): "The questions explored areas I would not have thought of on my own. The questions focused on the key concepts of a system." and "The applicable questions where very insightful and invoked lots of back and forth discussion." The most frequent reason for not getting much insight was insufficient domain knowledge (7\%). Students got the best insights into the individual dimension, followed by environmental and technical. No dimension was particularly problematic. To get more information on insights, we also asked students whether anything unexpected came up. Only $26 \%$ reported unexpected occurrences, the most common being new perspectives (8\%) and effects of the system (8\%).

Finally, the third survey question asked the interviewees perceptions on whether the questions had been useful for triggering relevant discussions on the possible effects of software system (a.7). Interviewees from both universities strongly supported (5.0) this notion. E.g. one student 
mentioned "Yes, we discussed many topics triggered by the questions asked.". A majority of students confirmed that the interviewees found the questions helpful to expand on the topic, to think towards the future, and to discuss in more detail. Helpful pointers towards exploring environmental aspects and privacy were mentioned. The reasons for reporting less usefulness were that some questions were not relevant for that particular system (9\%) and that the interviewees did not consider themselves sufficiently knowledgeable (5\%). Students from LUT often focused on discussing the future, while group A answered more diversely and made more use of the proposed questions.

Intermediate conclusion: The answers suggest that these two studies support (4.07) RQ1. That is, that the questions enabled relevant discussions, both for the interviewers and interviewees, and led to insightful findings.

RQ2: Does the framework help to identify the potential chain of effects of software systems on sustainability?

Two survey questions contributed to this RQ. We summarize their answers below, adding insights from complementary questions to contextualize the answers.

The first survey question asked whether the SusAD questions helped to identify possible effects (b.2), students for both universities supported (4.01) this notion, 35\% stating that the questions helped very much, $46 \%$ that the helped, and $19 \%$ that helped a little bit ${ }^{1}$. Students from LUT had more difficulty than students from CSULB. In order to get more information, we asked how easy it was to identify the effects of each dimension separately. The most problematic one was the economic dimension, followed by the social, environmental, individual and technical, in this order. We also asked what else would have helped to identify possible effects. The two primary responses were around using additional research outside of the interviews, such as online sources $(15 \%)$, and more interviewees (12\%). Furthermore, side conversations, data trends, and more knowledgeable interviewees would have helped individual respondents.

When asked whether interviewees had been able to think of chains of effects for the extreme scenario (a.5), the overall answer was inconclusive (supported by LUT students but inconclusive for CSULB). To explore this further, students were asked for how many topics (in Table 1) interviewers were able to think of chains-of-effect: $78 \%$ thought of chains of effect for up to three key topics, $8.5 \%$ for 4 - 5 topics, and only $3.5 \%$ for more than five topics.

To see if the extreme scenario helped interviewees to think of chains-of-effect, we asked whether the students had encouraged the interviewee to think about the extreme scenario and about effects across dimensions. We observe that those with difficulties in identifying chains-of-effect were less encouraged to think about the extreme scenario and cross-dimensional effects. The opposite is also true, as shown in Table 7. In addition, the more the intervie-

1. For historical reasons (to allow a comparison with a previous work outside of the scope of this paper) this question allowed a yes/no answer and was complemented to get the degree to which the questions helped. For this reason, the calculation of the results was slightly different, with a "no"=1, "a little bit"=3", "helped"=4 and a "very much"=5. wee was encouraged to think of an extreme scenario and across dimensions, the greater the number of topics (s)he identified chains-of-effect for. This correlation is shown in Table 8. These suggest that the extreme scenario and the encouragement given by the interviewee are indeed useful to identify chains-of-effect. Finally, we also asked for how many topics (in Table 1) interviewers were able to think of chains-of-effect. $78 \%$ of the interviewees thought of chains of effect for up to three key topics, $8.5 \%$ for four-five topics, and only $3.5 \%$ for more than five topics. Interestingly, the more the interviewee was encouraged to think of an extreme scenario and across dimensions, the greater the number of topics he or she identified chains-of-effect to. This was also observed by students, who stated that "Giving them to consider of chains of effects allows for their thought process to expand past just one dimension" and "All these things are interrelated and are necessary to examine when researching a topic like this." Finally, around $30 \%$ of the students admitted to not having asked the interviewee to consider the extreme scenario. The primary reasons for not doing so varied greatly. The most cited were that it was that is was difficult to include the questions (5\%) and that the extreme scenario was not relevant for the system (5\%).

\begin{tabular}{l|l|l}
$\begin{array}{l}\text { Ability to think of } \\
\text { chains-of-effects }\end{array}$ & $\begin{array}{l}\text { Encouraged to think about } \\
\text { the extreme scenario }\end{array}$ & $\begin{array}{l}\text { Encouraged cross di- } \\
\text { mensional thinking }\end{array}$ \\
\hline $1-2$ & 2.39 & 1.78 \\
$4-5$ & 4.03 & 3.19 \\
TABLE 7. CORRELATION OF ENCOURAGEMENT AND EASE TO THINK \\
OF CHAINS OF EFFECT (SMALLER NUMBER = GREATER DIFFICULTY \& \\
LESS ENCOURAGEMENT)
\end{tabular}

\begin{tabular}{l|l|l}
$\begin{array}{l}\text { Normalized number } \\
\text { of topics }\end{array}$ & $\begin{array}{l}\text { Encouraged to think about } \\
\text { the extreme scenario }\end{array}$ & $\begin{array}{l}\text { Encouraged cross di- } \\
\text { mensional thinking }\end{array}$ \\
\hline 1 & 2.8 & 2.1 \\
2 & 3.4 & 2.7 \\
3 & 4.2 & 3.7 \\
4 & 5.0 & 4.4 \\
TABLE 8. CORRELATION OF ENCOURAGEMENT AND NUMBER OF \\
\multicolumn{2}{c}{ TOPICS WITH CHAINS-OF-EFFECT (SMALLER NUMBER = LESS } \\
\multicolumn{2}{c}{ ENCOURAGEMENT) }
\end{tabular}

Intermediate conclusion: The answers suggest that these two studies support (3.76) RQ2. That is, the questions help to identify effects and chains-of-effects, highlighting the importance of the extreme scenario and the encouragement to think across dimensions.

RQ3: How practical is the proposed approach?

Seven survey questions contributed to this RQ.

The first survey question refers to whether the interviewee understood the questions (a.1). Students from both universities supported (4.08) this idea. However, about 1/4 of the students pointed out that there were questions with unclear definitions, which points out the need to review and refine the questions. The questions that caused greater confusion were about the supply chain (23\%) and agency $(11 \%)$. No dimension was particularly problematic. Also, $10 \%$ of the students felt that some questions were not relevant to the system at hand. This was expected; in creating a general framework, we knew we could neither be specific to a domain nor comprehensive. 
The second survey question refers to interviewee's view on whether the questions were easy to understand (a.2). Interviewees from both universities supported (3.64) this notion. One interviewee mentioned "Yes, the questions got me thinking about change and the decisions we have to make for a sustainable future." Furthermore, responses indicate that some questions were perceived as vague (12\%), again showing the need for reviewing and refining the sheets. Other interviewees felt that some questions were not relevant for the system under analysis (9\%), or they needed time to be interpreted $(7 \%)$.

The third survey question refers to the interviewer's perceptions on whether the interviewee could understand the questions (a.6). The answer to this question was inconclusive (-2.76), with the data showing that the students from LUT opposed the notion while no conclusion could be drawn for CSULB. One possible contributor to the worse perception in LUT was that the students received the questions in English, but conducted the interviews in Finnish. It is also interesting to note the following differences: interviewees themselves felt they understood the questions, while interviewers thought otherwise. The greater difficulties reported by students were that some questions had no relation with the system (15\%); e.g. one student said "Difficult to get a conversation going about the topic, the interviewee did not consider there to be much to discuss". Other reported difficulties were lack of knowledge of the interviewee (10\%) and the wording of the questions (9\%). To get a deeper understanding of their answers, we asked whether students had interviewed an expert or a surrogate. Overall, about $70 \%$ of the interviewees were surrogates, and $30 \%$ had knowledge or expertise on the topic. We found little correlation between the level of expertise and the observed difficulty in understanding the questions.

The fourth survey question refers to whether the students felt that they got access to the right stakeholders (b.1). The overall result was inconclusive (3.3), with a 'support' from CSULB and an 'inconclusive' from LUT. Of the five dimensions, both groups found it easiest to get access to relevant stakeholders for the individual and technical dimensions. Experts for the economic dimension proved hardest to obtain for both groups.

The fifth survey question refers to whether the students liked the process of asking the questions (b.3), noting down the key points and showing them back to the interviewee. Data was inconclusive (2.83), with students from CSULB opposed to the practice and LUT supporting it. The reasons why subjects liked and disliked the process varied greatly. The reasons for positive ratings were that subjects liked interviewing (12\%) and found it to be a good practice (8\%), while the main reason for disliking it was that they felt it was redundant $(12 \%)$. In order to put these answers into context, we should note that $34 \%$ of the students in CSULB and $50 \%$ of the students in LUT had not used the form at all as they did not find it useful (12\%), had forgotten to bring it $(8 \%)$, or had made their own sheet $(8 \%)$. Using the form could also have contributed to the number of chains-of-effect that the interviewee was able to think of since the students were expected to show the form back to the interviewer in order to ask them about the extreme scenario.

The sixth survey question asks about whether the SusAD questions helped to fill out the Sustainability Awareness Diagram (b.4). Both universities supported this notion. Some students found the questions helpful for the diagram (9\%) and to extract key points (7\%): "Answers were straight forward, so the points were easy to establish on the SusAD." Only two respondents mentioned a negative impact in that certain questions could lead to bias $(2 \%)$ and that they were too direct $(2 \%)$.

The last survey question asks whether the resulting SusAD was readable (b.5). Students from both universities supported this idea (3.92). The three main explanations were that the diagram was readable $(23 \%)$, the students decided only to include key points (15\%), and that they were able to make links (12\%).

Finally, the last point worth commenting is the time of the interviews. Most of them took between 15 and 30 minutes $(52 \%)$, followed by 30 to 60 minutes $(27 \%)$, and by less than 15 minutes (12\%). Even though the interviewees who identified most chains-of-effect had also talked for longer, no clear correlation was found between the time of the interview and the number of chains-off-effect identified.

Intermediate conclusion: The answers suggest that these two studies support (3.42) RQ3. That is, on their own perceptions, both interviewers and interviewees understood the questions, thought they helped to fill out the SusAD, and that the latter was readable.

Overall, the feasibility studies support the three research questions. Questions can be understood, enable discussion and interesting insights, help to identify chains-of-effect (especially when the extreme scenario is used), and finally are reasonably practical in terms of time, the wording of the questions and the resulting diagram. Yet, there is still room for improvement in the process and on some questions.

\section{Related work}

While traditional RE methods and tools do not explicitly facilitate the discussion of sustainability-related concerns, research suggests that existing RE techniques, approaches and methods can serve as a starting point for practitioners to integrate sustainability into their practice [8]. Chitchyan et al., [12] identified several techniques that help to support sustainability in RE and demonstrated the application of some of these techniques using two case studies. Similarly, Mireles et al., [20] proposed a conceptual framework for the classification of sustainability-aware requirements methods to support practitioners in the selection of an appropriate method to address stakeholders' needs.

A number of studies have attempted to integrate sustainability into specific methods and techniques. Seyff et al., [28] extended the WinWin Negotiation Model to consider the impact of requirements on sustainability. The results of the study suggested that while the approach stimulated the discussion on the multiple dimensions of sustainability, stakeholders found it challenging to identify 
the impacts of a given requirement on sustainability and were not able to identify the long-term effects. Cabot et al., [8] proposed using $\mathbf{i}^{*}$ for modelling early requirements as a way to visualise the impact of alternative options on sustainability goals and to analyse the conflicts between sustainability and other problem-specific objectives. Similarly, Mussbacher and Nuttall [21] argue that goal models are an ideal candidate to model the assessment of alternatives for sustainability as they express the hierarchy of needs from high-level goals to specific activities for various stakeholders,also allowing reasoning about alternatives and their impact on high-level goals. In contrast to Cabot et al. [8], they proposed a method to combine Goal-oriented Requirement Language (GRL) because of its support for indicators with a quantitative sustainability assessment approach based on time cost that would be applicable to a broad range of development projects. However, no formal evaluation of either method was conducted to demonstrate their efficacy.

Brito et al., [6] proposed a concern-oriented requirements approach that allows both the modelling of sustainability concepts and their relationships and the management of conflicting situations triggered by impacts among sustainability dimensions or between those and other system concerns. In contrast to the previous studies, Penzenstadler et al. [23] explored how the concept of leverage points could be used to make sustainability issues more tangible in system design in a public transportation system [29]. However, both approaches do not discuss the role of requirements engineering for sustainability engineering.

In addition, a number of alternative approaches have been proposed, including the use of a recommender system to overcome the barriers of incorporating sustainability into the software engineering process [25], the application of a sustainability requirement pattern to guide the specification of sustainability requirements [26], a tool for requirement engineers to analyse the requirements' impacts on system sustainability [2], and a meta-model which integrates sustainability dimensions with the other quality attributes [27].

\section{Discussion and Conclusions}

This paper highlights that the software developed today does not exist in isolation but forms part of the sociotechnical system within which it gets used. Thus, the paper advocates that requirements engineers must tackle concerns of sustainability of such socio-technical systems, starting from the time when software requirements are elicited and specified. A number of issues have implicitly motivated this work and remain topics for an open discussion:

SusAD as a Systems Thinking activity: The proposed Sustainability Awareness framework, essentially, incorporates simplified elements of Systems Thinking [19] activities into the RE process. Like the systems thinking disciplines, our work advocates consideration of the holistic system within which the software-to-be will function, attending not only to the functional and non-functional properties of the software system but also to the indirect, longer-term impacts that its use could cause and considering the risks and uncertainties that this may engender. However, we are also well aware that the discipline of software engineering already suffers from high costs and late delivery problems, and additional "whole systems" analysis could prove too costly and complex to be useful. In truth, this very problem stifles the use of techniques such as Soft Systems [10] methodology or Critical Systems Thinking [15] in the software engineering domain. To avoid both unbounded complexity and cost, our approach supports the exploration of potential sustainability impacts through both simple guiding question sets and impact recording tools and an elicitation scenario. This allows to keep the focus on identification of sustainability effects across three orders of effect, yet provides a boundary to the otherwise potentially overwhelming systems thinking and analysis task.

Systems vs Software Requirements Engineering: It has long been recognised that any systems engineering project requires a requirements engineering activity. Indeed, requirements engineers working within the systems engineering domains (such as construction, and chemical process engineering) are well attuned to the systemic impact analysis. Yet, this is too often amiss within SE, where RE has too often limited itself to software requirements engineering, disregarding the wider implications that the software could cause. We hope that this paper has motivated sufficiently clearly (using the Airbnb platform example) the need to tackle such disregard of the socio-technical impacts of software systems. In this paper, we provide a simple framework to take the first steps in addressing this omission.

Requirements Engineers as leads for Sustainability Engineering: Researchers have previously argued [3] that requirements shape the software systems, which, in turn, shape the socio-technical systems within which they reside. As such, if so engineered, software systems could become the drivers towards sustainable societal, environmental, and economic settings. Thus, the present work endeavours to support requirements engineers in taking on the role of sustainability engineers, through timely consideration and fostering informed choices in tackling the challenge of the socio-technical systems requirements engineering.

In conclusion, we found evidence that the Sustainability Awareness Framework presented in this paper provides a simple and accessible framework to elicit awareness of the impacts that software systems could have. I.e., it could be used by students independently and without previous knowledge. Carver argues that students are a close enough representation for practitioners [?]. Having evaluated the questions that guide such awareness-building activity with two sets of student groups, we find sufficient evidence that the questions and elicitation scenario provide the desired support. Yet, much work remains to be done, including improving the clarity of the questions, supporting impact visualisation (currently done manually), and considering the specialisation of the questions per relevant application domains, studying the framework across different cultures, etc. 


\section{Acknowledgments}

The research leading to these results has received funding from the EU Horizon 2020 research and innovation programme under the Marie Skodowska-Curie grant agreement No 712949 (TECNIOspring PLUS) and from the Agency for Business Competitiveness of the Government of Catalonia, EPSRC grant EP/R007373/1, Digitaldialog 21 funded by the Ministry for Science, Research and Art Baden-Wrttemberg. Each named author made a significant contribution both in terms of ideas, discussions, evolution, and physical writing to be named on the paper. All authors participated in the design and development of the framework applied in the study. The authors would also like to thank Dr. Christoph Becker for insights that led us to change the focus from an analytic to an awareness framework, and Ms. Nanae Aubry for helping with part of the coding of the feedback forms.

\section{References}

[1] Airbnb, inc. http://www.airbnb.com, 2019. Accessed: 2019-03-01.

[2] A. D. Alharthi, M. Spichkova, and M. Hamilton. Susoftpro: Sustainability profiling for software. In IEEE 26th International Requirements Engineering Conference (RE), pages 500-501, Aug 2018.

[3] C. Becker, S. Betz, R. Chitchyan, L. Duboc, S. Easterbrook, B. Penzenstadler, N. Seyff, and C. Venters. Requirements: The key to sustainability. IEEE Software, 33(1):56-65, 2016.

[4] C. Becker, R. Chitchyan, L. Duboc, S. Easterbrook, M. Mahaux, B. Penzenstadler, G. Rodriguez-Navas, C. Salinesi, N. Seyff, C Venters, C. Calero, S. Akinli Kocak, and S. Betz. Karlskrona manifesto on sustainability design, 2015. https://www.sustainabilitydesign.org/.

[5] C. Becker, R. Chitchyan, L. Duboc, S. Easterbrook, B. Penzenstadler, N. Seyff, and C. Venters. Sustainability design and software: The karlskrona manifesto. In Proceedings of the 37th Intl Conference on Software Engineering-Volume 2, pages 467-476. IEEE Press, 2015.

[6] I. S. Brito, J. M. Conejero, A. Moreira, and J. Arajo. A concernoriented sustainability approach. In 2018 12th International Conference on Research Challenges in Information Science (RCIS), pages 1-12, May 2018.

[7] Gro Harlem Brundtland, M Khalid, S Agnelli, et al. Our common future. New York, 1987.

[8] J. Cabot, S. Easterbrook, J. Horkoff, L. Lessard, S. Liaskos, and J. Mazon. Integrating sustainability in decision-making processes: A modelling strategy. In 31st International Conference on Software Engineering - Companion Volume, pages 207-210, May 2009.

[9] P. Checkland. Systems thinking. Rethinking management information systems, pages 45-56, 1999.

[10] P. Checkland and Poulter J. Learning for Action: A Short Definitive Account of Soft Systems Methodology and its Use, for Practitioners, Teachers and Students. John Wiley and Sons Ltd, 2006.

[11] R. Chitchyan, C. Becker, S. Betz, L. Duboc, B. Penzenstadler, N. Seyff, and C. Venters. Sustainability design in requirements engineering: state of practice. In Proceedings of the 38th Intl Conference on Software Engineering Companion, pages 533-542. ACM, 2016.

[12] R. Chitchyan, S. Betz, L. Duboc, B. Penzenstadler, S. Easterbrook, C. Ponsard, and C. Venters. Evidencing sustainability design through examples. In Proceedings of the 4th Intl. Workshop on Requirements Engineering for Sustainable Systems, 2015.

[13] Duboc L.; Betz S.; Penzenstadler B.; Akinli Kocak S.; Chitchyan R.; Leifler O.; Porras J.; Seyff N.; Venters C. Supplementary materials, 2019. https://www.sustainabilitydesign.org/susad-forms/.
[14] S. Easterbrook. From computational thinking to systems thinking: A conceptual toolkit for sustainability computing. In ICT for Sustainability 2014 (ICT4S-14), Stockholm, Sweden, 2014.

[15] M.. Goodchild and D. Janelle. Toward critical spatial thinking in the social sciences and humanities. GeoJournal, 75(1):3-13, Feb 2010.

[16] L. Hilty and B. Aebischer. Ict for sustainability: An emerging research field. In ICT Innovations for Sustainability, pages 3-36. Springer, 2015.

[17] J. Landeta. Current validity of the delphi method in social sciences. Technological Forecasting and Social Change, 73(5):467 - 482, 2006.

[18] P. Mayring. Qualitative content analysis: theoretical foundation, basic procedures and software solution. 2014.

[19] D. Meadows. Thinking in Systems: A Primer. Chelsea Green Publishing, 2008.

[20] G. A. G. Mireles, M. . Moraga, F. Garca, and M. Piattini. A classification approach of sustainability aware requirements methods. In 2017 12th Iberian Conference on Information Systems and Technologies (CISTI), pages 1-6, June 2017.

[21] G. Mussbacher and D. Nuttall. Goal modeling for sustainability: The case of time. In IEEE 4th International Model-Driven Requirements Engineering Workshop (MoDRE), pages 7-16, Aug 2014.

[22] C. Okoli and S. Pawlowski. The delphi method as a research tool: an example, design considerations and applications. Information \& Management, 42(1):15 - 29, 2004.

[23] B. Penzenstadler, L. Duboc, C. C. Venters, S. Betz, N. Seyff, K. Wnuk, R. Chitchyan, S. M. Easterbrook, and C. Becker. Software engineering for sustainability: Find the leverage points! IEEE Software, 35(4):22-33, July 2018.

[24] B. Penzenstadler, A. Raturi, D. Richardson, and B. Tomlinson. Safety, security, now sustainability: The nonfunctional requirement for the 21st century. IEEE software, 31(3):40-47, 2014.

[25] K. Roher and D. Richardson. A proposed recommender system for eliciting software sustainability requirements. In 2013 2nd International Workshop on User Evaluations for Software Engineering Researchers (USER), pages 16-19, May 2013.

[26] K. Roher and D. Richardson. Sustainability requirement patterns. In 2013 3rd International Workshop on Requirements Patterns (RePa), pages 8-11, July 2013.

[27] T. Saputri and S. Lee. Incorporating sustainability design in requirements engineering process: A preliminary study. In Asia Pacific Requirements Engineering Conference, pages 53-67. Springer, 2016.

[28] N. Seyff, S. Betz, L. Duboc, C. Venters, C. Becker, R. Chitchyan, B. Penzenstadler, and M. Nbauer. Tailoring requirements negotiation to sustainability. In 2018 IEEE 26th International Requirements Engineering Conference (RE), pages 304-314, Aug 2018.

[29] UK Commission for Integrated Transport. Transport and climate change: Advice to government from the commission for integrated transport. http://www.cambridgeenergy.com/archive/2007-02-08/ commission-integ-trans.pdf, 2007.

[30] C. Venters, C. Jay, L. Lau, M. Griffiths, V. Holmes, R. Ward, J. Austin, C. Dibsdale, and J. Xu. Software sustainability: The modern tower of babel. CEUR Workshop Proceedings, 1216:7-12, 2014.

[31] C. Venters, Seyff N., Becker C., Betz S, Chitchyan R., Duboc L., Mcintyre D., and Penzenstadler B. Characterising sustainability requirements: A new species, red herring, or just an odd fish? In IEEE/ACM 39th Intl Conference on Software Engineering, pages 312. Institute of Electrical and Electronics Engineers Inc., 62017.

[32] D. Wachsmuth and A. Weisler. Airbnb and the rent gap: Gentrification through the sharing economy. Environment and Planning A: Economy and Space, 50(6):1147-1170, 2018.

[33] C. Wohlin, P. Runeson, M. Hst, M. Ohlsson, B. Regnell, and A. Wessln. Experimentation in Software Engineering. Springer Publishing Company, Incorporated, 2012. 